\title{
Successful ageing in Singapore: prevalence and correlates from a national survey of older adults
}

\author{
Mythily Subramaniam ${ }^{1}$, MBBS, PhD, Edimansyah $\underline{\text { Abdin }}^{1}$, PhD, Janhavi A Vaingankar ${ }^{1}$, MSc, Rajeswari Sambasivam ${ }^{1}$, BSc, \\ Esmond Seow ${ }^{1}$, вA, Louisa Picco' ${ }^{1}$, MPH, Hong Choon Chua ${ }^{2}$, MBBS, MMed, Rathi Mahendran ${ }^{3}$, MBBS, MMed,
} Li Ling $\mathrm{Ng}^{4}$, MBBS, MMed, Siow Ann Chong ${ }^{1}$, MBBS, MMed

INTRODUCTION The current study aimed to estimate the overall prevalence and sociodemographic correlates of successful ageing, as defined by Rowe and Kahn, among a national sample of multiethnic adults aged 60 years and older in Singapore. METHODS Data from older adults who participated in the Well-being of the Singapore Elderly study was analysed. Successful ageing was defined with five indicators: no major diseases; no disability; high cognitive functioning; high physical functioning; and active engagement with life.

RESULTS The prevalence of successful ageing was $25.4 \%$ in this older population. Older adults aged $75-84$ years and $\geq 85$ years had 0.3 times and 0.1 times the odds of successful ageing, respectively, than those aged 60-74 years. Compared to older adults of Chinese ethnicity, those of Malay (odds ratio [OR] 0.6) and Indian (OR 0.5) ethnicities were less likely to be associated with successful ageing. Older adults with lower education levels, who had no formal education (OR 0.2), some schooling but did not complete primary education (OR 0.4) or only primary education (OR 0.5 ), had lower odds of ageing successfully than those with tertiary education.

CONCLUSION Older adults in Singapore tend to have much more active engagement with life as compared to their counterparts from other countries. Further research into this population is needed, both in terms of qualitative research to gain a better understanding of successful ageing from the older adult's perspective, as well as longitudinal studies that explore behavioural determinants of successful ageing.

Keywords: Asian, multiethnic, prevalence, successful ageing

\section{INTRODUCTION}

Rowe and Kahn defined successful ageing as the "avoidance of disease and disability, maintenance of high physical and cognitive function, and sustained engagement in social and productive activities". Researchers have distinguished successful ageing from 'usual ageing', where the latter is characterised by a decline in physical, mental and social functioning. ${ }^{(1)}$

Other variants of the term 'successful ageing' have been used to define the phenomenon, such as 'healthy ageing', (2) 'optimal ageing ${ }^{(3)}$ and 'productive ageing'. (4) Successful ageing has also been variously defined by other researchers. Pruchno et al put forth a two-factor model of successful ageing that comprises an objective and a subjective component. The objective component included having fewer chronic diseases, ample functional ability and little/no pain, while the subjective component took into consideration the older persons' own evaluation of how well they were ageing, how successful their ageing experience was and the extent to which they rated their current life as positive. ${ }^{(5)}$ Bowling emphasised the need for a multidimensional model of successful ageing that takes into consideration the respondents' self-report of health status and quality of life, and advocated the need to balance the biomedical perspective with a psychosocial perspective, and vice versa. ${ }^{(6)}$ Phelan et al similarly concluded that older adults perceive successful ageing as a multidimensional concept that encompasses physical, functional, psychological and social health. ${ }^{(7)}$

While successful ageing has been described quite diversely in the literature, it has also been regarded as a "calculable gold standard of ageing" ${ }^{\prime \prime}{ }^{(8)}$ and many studies have used this concept to characterise the population of older adults. For instance, McLaughlin et al who used data from the Health and Retirement Study from the United States (US) to establish the prevalence of successful ageing at four time points, reported prevalence rates of $11.9 \%$ in 1998 and $2000,11.0 \%$ in 2002, and $10.9 \%$ in 2004 among adults aged $\geq 65$ years, in accordance with Rowe and Kahn's definition. ${ }^{(9)}$ Hank used data from respondents aged $\geq 65$ years who participated in SHARE (Survey of Health, Ageing and Retirement in Europe), a study that included 14 European countries and Israel, and found that the average prevalence of successful ageing was $8.5 \%$, with significant variation among countries - from $21.1 \%$ in Denmark to 3.1\% in Spain and $1.6 \%$ in Poland. ${ }^{(10)}$ Examining data from the China Health and Retirement Study conducted in adults aged $\geq 60$ years, Liu et al estimated a $13.2 \%$ prevalence of successful ageing in this population. ${ }^{(11)}$ These studies identified that younger age, male gender, higher education and higher income were associated with successful ageing.

Singapore is a multiethnic country located at the southern tip of the Malay Peninsula in Southeast Asia. It has a resident

${ }^{1}$ Research Division, ${ }^{2} \mathrm{CEO}$ Office, Institute of Mental Health, ${ }^{3}$ Department of Psychological Medicine, National University Hospital, ${ }^{4}$ Department of Psychological Medicine, Changi General Hospital, Singapore

Correspondence: Dr Mythily Subramaniam, Director, Research Division, Institute of Mental Health, Buangkok Green Medical Park, 10 Buangkok View, Singapore 539747. Mythily@imh.com.sg 
population of 3.9 million people, comprising those of Chinese, Malay, Indian and other ethnicities. Singapore's population has grown older over the years. In 2015, older adults (i.e. aged $\geq 65$ years) made up $11.8 \%$ of the population. ${ }^{(12)}$ The average life expectancy at birth is 82.7 years and the median age of the resident population rose from 34.0 years in 2000 to 39.6 years in 2015. ${ }^{(12)}$ Data suggests that Singapore will meet the World Health Organization's criteria for an aged society (14\% residents over the age of 65 years) within the next five years. ${ }^{(13)}$

Cultural values play an important role in shaping older adults' perception of successful ageing. However, few studies have examined their role in ageing or made cross-cultural comparisons in Singapore. Using a qualitative approach, Nagalingam explored the concept of successful ageing and the factors affecting it among older Indian adults in Singapore. Most of the respondents cited health status and the need to keep healthy via exercises and diet control as components of successful ageing. Respondents also identified religiosity, financial resources and social support as some of the other key factors for successful ageing. ${ }^{(14)}$ Using a similar qualitative approach among older adults in Malaysia, Tohit et al identified spirituality, physical health and functioning, peace of mind, financial independence, family and living environment as major themes associated with healthy ageing. ${ }^{(15)}$ Through focus group discussions conducted with Chinese, Indian and Malay older adults, Gwee identified six interrelated themes - physical and cognitive wellbeing; harmonious family relations; meaningful social engagement and network; positive adaptation and emotional wellness; positive spirituality; and sufficient financial resources and autonomy - as important for successful ageing. The author also identified some ethnic differences among the respondents: Chinese and Indian respondents cited health as the most important factor in ageing successfully, while the majority of Malay respondents considered religion to be the most important factor. ${ }^{(16)}$ Using a multidimensional concept of ageing, $\mathrm{Ng}$ et al used data from 1,281 community-dwelling older adults ( $\geq 65$ years) of Chinese ethnicity, who were largely drawn from the southeast regions of Singapore and were part of the Singapore Longitudinal Ageing Study cohort. They found that $28.6 \%$ of respondents met the criteria for successful ageing, which was associated with younger age, female gender, better education, better housing, having religious or spiritual beliefs, physical activities and exercise, and low or no nutritional risk. ${ }^{(17)}$

However, to date, there is no data on successful ageing that includes a representative sample of Singapore's multiethnic population or uses Rowe and Kahn's criteria. Such data could help us make cross-cultural comparisons and also provide a comprehensive understanding of the phenomenon of successful ageing at a national level. Therefore, the current study aimed to: (a) estimate the overall prevalence of successful ageing, as defined by Rowe and Kahn, among a national sample of multiethnic adults aged $\geq 60$ years in Singapore; and (b) establish the sociodemographic correlates of successful ageing in this population.

\section{METHODS}

The Well-being of the Singapore Elderly (WiSE) study was a comprehensive, single-phase, cross-sectional national survey that aimed to determine the prevalence of dementia among older adults (aged $\geq 60$ years) in Singapore. Respondents were randomly selected using a disproportionate stratified sample design via a national registry that maintains details about sociodemographic correlates, such as age, gender, ethnicity and addresses of all Singapore residents. The sampling frame for the study comprised Singapore residents (including Singapore citizens and permanent residents) aged $\geq 60$ years who were living in Singapore at the time of the survey. The sample was inclusive of residents who were in day care centres, nursing homes and institutions at the time of the survey. Older adults attending day care centres were interviewed at their venue of choice, either at their home or day care centre. For respondents who were reported to be living in nursing homes or institutions when their households were approached, the interviewer contacted the nursing home or institution using information provided by the family members and made an appointment with the older person after obtaining the relevant consent(s). The study also included an informant (i.e. a person who knew the respondent best) who was administered specific questionnaires.

Sample size estimates were based on establishing the prevalence of dementia using the prevalence estimates of $5.2 \%$, as described in a previous study. ${ }^{(18)} \mathrm{A}$ target sample size of 2,500 was estimated to provide sufficient precision to measure the prevalence of dementia in the population. The study was approved by the relevant ethics committees (National Healthcare Group Domain Specific Review Board and SingHealth Centralised Institutional Review Board), and all respondents and informants provided written informed consent. In situations where the respondents were unable to provide informed consent, written informed consent was obtained from their legally acceptable representative or next of kin. The WiSE study has been described in greater detail in a previous article. ${ }^{(19)}$

Guided by Rowe and Kahn's conceptualisation, ${ }^{(1)}$ successful ageing was defined as having: (a) no major diseases; (b) no disability in activities of daily living (ADLs); (c) no more than one difficulty with seven measures of physical functioning; (d) a median or higher score on tests of cognitive functioning; and (e) active engagement with life (e.g. work, social or community activities).

To identify participants who had no major diseases, participants were asked whether a doctor had ever diagnosed them with any of the conditions in a list of chronic medical conditions that are considered prevalent in Singapore, including diabetes mellitus, heart disease, stroke, cancer and chronic lung disease. A diagnosis of depression was made using the Automated Geriatric Examination for Computer Assisted Taxonomy (AGECAT). ${ }^{(20)}$ The study used Stage 1 Geriatric Mental StateAGECAT depression syndrome for this analysis. ${ }^{(21)}$ Respondents who did not report any of the above five major chronic physical conditions, or depression, were considered as having met the criterion. 
Respondents who met the criterion of having no disability did not report difficulty performing any of the following ADLs: dressing, bathing or showering, grooming, eating, using the toilet and performing household activities.

Participants were deemed to have high physical functioning if they: (a) had no problem standing for long periods (e.g. half an hour); (b) reported no difficulty in walking a distance of $1 \mathrm{~km}$; (c) described themselves as very or fairly physically active; (d) had a higher-than-median grip strength $(20.0 \mathrm{~kg})$, as measured by the JAMAR® Plus+ hydraulic hand dynamometer, ${ }^{(22)}$ (e) were observed to have no problems with fine finger movement (touching the thumb to the four digits sequentially several times); (f) did not show a positive pronator drift (Barre sign); and (g) were not classified as having slow gait (defined as a walking speed of one standard deviation below the age- and gender-specific mean gait of the sample). ${ }^{(23)}$ Although the measures of high physical functioning in our study were not identical to those of other studies, ${ }^{(9-11)}$ they have been used by other researchers as measures of physical functioning for successful ageing. ${ }^{(24)}$

To measure cognitive functioning, a cognitive test battery comprising: (a) the Community Screening Instrument for Dementia, ${ }^{(25)}$ which incorporated the Consortium to Establish a Registry for Alzheimer's Disease (CERAD) animal naming verbal fluency task; and (b) the modified CERAD ten-word list learning task with delayed recall ${ }^{(26)}$ was administered to all participants. This generated the global cognitive score, an item-weighted total score from the cognitive test. Participants could obtain a maximum score of 34. A median (29.7) score or higher denoted high cognitive functioning.

Participants were defined as actively engaged with life if they reported: (a) 'doing any work for pay at the present time', or 'participating in any religious, community or social meeting'; OR (b) any one of the following social connections: being married, having 'good friends living in (their) neighbourhood', or 'getting together with... neighbours or friends just to chat' at least once a week.

Sociodemographic data on age, gender, ethnicity, education and income was collected. Height and weight were measured by trained field interviewers. During the measurement, participants wore indoor clothing without shoes, while interviewers used a tape measure and a digital standing scale that was calibrated before every use. Height was measured by asking respondents to stand against a wall with their feet together and their heels, back and back of the head touching the wall. They were then asked to look straight ahead with their chin tucked in. The top of their head was then marked lightly with a pencil, and a tape measure was used to measure the distance from the floor to the mark. Weight was measured by asking respondents to step on the weighing scales and look straight ahead. Interviewers were trained in measuring height and weight accurately as part of their training in study procedures. Body mass index (BMI) was calculated using a formula: weight in kilograms divided by the square of height in metres $\left(\mathrm{kg} / \mathrm{m}^{2}\right)$. Self-reported health status was assessed by asking the respondents: "How do you rate your overall health in the past 30 days?" The answer was further categorised as 'very good', 'good' and 'moderate', versus 'bad' and 'very bad'. To confirm their smoking status, respondents were asked if they ever smoked, and those who replied in the affirmative were asked whether they were still smoking regularly. Those who answered 'yes' to the question were classified as current smokers and those who answered 'no' were classified as ex-smokers. ${ }^{(27)}$

All the instruments were available in English as well as in Chinese, Malay and Tamil. Interviewers were trained in the ethical aspects of conducting a research study and the administration of instruments over a two-week period. A senior member of the research team assessed each interviewer for proficiency and skills upon completion of the interviewer training. Only interviewers who met the team's criteria were allowed to continue with the fieldwork. Field observations were conducted throughout the duration of the study. Video recordings of training interviews were made available to the interviewers on their iPads to help them revise the methodology whenever needed. Monthly debriefs were also conducted to identify problem areas and the need for retraining or revision of processes. Well-trained dialect-speaking interviewers also administered the translated questionnaires in Hokkien, Teochew or Cantonese, when needed. The choice of language used in the interview depended on the respondent's expressed preference.

Statistical analyses were carried out using SAS System version 9.3 (SAS Institute Inc, Cary, NC, USA). All data analyses were performed using weighted data to adjust for oversampling, and post-stratified for age and ethnicity distributions between the survey sample and the older adult resident population in Singapore. A series of multiple logistic regression models were used to examine the sociodemographic correlates of successful ageing and each individual criterion for successful ageing. Associations between successful ageing and other outcome measures - including overall health, smoking status and BMI, with adjustment for confounding sociodemographic variables such as age, gender, ethnicity, and income and education status - were examined using multiple logistic and linear regression analyses. To account for the effects of complex sample design due to stratification and weighting, standard errors and significance tests were estimated using the Taylor series linearisation method. Multivariate significance was evaluated using the Wald test, based on design-corrected coefficient variance-covariance matrices. Statistical significance was set at the conventional level of $\mathrm{p}<0.05$, using two-sided tests.

\section{RESULTS}

A total of 2,565 older adults were finally included in the present study, among whom the prevalence of successful ageing was $25.4 \%$. The percentage of older adults reporting no major diseases, high cognitive functioning, high physical functioning, no disability and active engagement with life was 55.3\%, $50.4 \%, 61.7 \%, 80.9 \%$ and $95.1 \%$, respectively. Table I shows the percentage of older adults that met each successful ageing criterion, according to sociodemographic characteristics. Table II shows the sociodemographic correlates of each successful ageing criterion. Age group, gender, ethnicity, income and 
Table I. Percentage of older adults who met individual successful ageing criterion, by sociodemographic factor.

\begin{tabular}{|c|c|c|c|c|c|}
\hline \multirow[t]{2}{*}{ Variable } & \multicolumn{5}{|c|}{ No. (weighted \%) } \\
\hline & $\begin{array}{l}\text { No major } \\
\text { diseases }\end{array}$ & $\begin{array}{l}\text { High cognitive } \\
\text { functioning }\end{array}$ & $\begin{array}{l}\text { High physical } \\
\text { functioning }\end{array}$ & $\begin{array}{l}\text { No } \\
\text { disability }\end{array}$ & $\begin{array}{l}\text { Active engagement } \\
\text { with life }\end{array}$ \\
\hline Overall sample & $1,243(55.3)$ & $1,016(50.4)$ & 1,269 (61.7) & 1,785 (80.9) & 2,349 (95.1) \\
\hline \multicolumn{6}{|l|}{ Age group (yr) } \\
\hline $60-74$ & 773 (58.8) & $831(60.1)$ & $974(70.4)$ & $1,250(87.8)$ & 1,462 (97.9) \\
\hline$\geq 85$ & $183(44.7)$ & $28(7.7)$ & 45 (12.9) & 118 (32.9) & $280(65.1)$ \\
\hline \multicolumn{6}{|l|}{ Gender } \\
\hline Male & $507(50.0)$ & $542(56.5)$ & 705 (71.8) & $856(85.6)$ & $1,078(97.0)$ \\
\hline Female & 736 (59.5) & 474 (45.5) & $564(53.8)$ & 929 (77.3) & 1,271 (93.5) \\
\hline \multicolumn{6}{|l|}{ Ethnicity } \\
\hline Malay & $379(51.0)$ & $236(39.3)$ & 309 (50.4) & 477 (73.2) & $674(94.5)$ \\
\hline Indian & 300 (39.0) & 318 (47.4) & 383 (56.2) & $521(73.1)$ & 722 (95.8) \\
\hline Other & $13(38.7)$ & $24(70.3)$ & $19(54.4)$ & $30(85.2)$ & $35(97.1)$ \\
\hline \multicolumn{6}{|l|}{ Income* (SGD) } \\
\hline$<500$ & $429(45.8)$ & $227(32.4)$ & 296 (39.2) & $529(64.7)$ & $842(88.0)$ \\
\hline $500-999$ & $230(54.8)$ & $179(46.5)$ & $255(65.0)$ & 361 (82.9) & $463(98.1)$ \\
\hline $1,000-1,999$ & 292 (61.4) & $282(57.2)$ & 366 (74.4) & 442 (87.8) & $518(99.0)$ \\
\hline$\geq 2,000$ & $196(61.8)$ & $262(75.0)$ & 273 (76.6) & $328(94.7)$ & $357(98.1)$ \\
\hline \multicolumn{6}{|l|}{ Education level $^{\dagger}$} \\
\hline None & $231(49.2)$ & $39(13.4)$ & $126(38.2)$ & $266(67.5)$ & $412(88.4)$ \\
\hline Did not complete primary & $293(53.0)$ & $143(32.8)$ & $272(57.4)$ & $406(79.1)$ & $557(94.1)$ \\
\hline Completed primary & $299(53.0)$ & $293(54.4)$ & $348(63.1)$ & $484(82.8)$ & 615 (97.6) \\
\hline Completed tertiary & 138 (59.7) & 198 (81.4) & $182(77.0)$ & $219(91.1)$ & $254(97.2)$ \\
\hline
\end{tabular}

*Based on National Survey of Senior Citizens 2011 report. †Data on education levels was not available for some respondents.

education status were significantly associated with the reporting of no major diseases and high physical functioning; age group, ethnicity, income and education status were associated with high cognitive functioning; age group, ethnicity and income status were significantly associated with the reporting of no disability; and age group and income status were significantly associated with active engagement with life.

The sociodemographic correlates of successful ageing were examined using logistic regression analysis and the results are presented in Table III. Older age was less likely to be associated with successful ageing - the odds of ageing successfully for older adults aged $75-84$ years and $\geq 85$ years were 0.3 times and 0.1 times, respectively, of that for participants aged $60-74$ years. Compared to participants of Chinese ethnicity, those of Malay (odds ratio [OR] 0.6) and Indian (OR 0.5) ethnicities were less likely to be associated with successful ageing. Compared to older adults earning below SGD 500 monthly, those earning SGD 500-999 (OR 2.0), SGD 1,000-1,999 (OR 2.1) and $\geq$ SGD 2,000 (OR 2.4) had higher odds of ageing successfully. Participants with lower education levels, who had no formal education (OR 0.2), some schooling but did not complete primary education (OR 0.4) or only primary education (OR 0.5), had lower odds of ageing successfully, as compared to those who had completed tertiary education. Table IV shows the relationship between successful ageing (and its individual criteria) and other health-related measures. After adjusting for age, gender, ethnicity, income and education status in the multiple logistic regression analysis, participants who reported successful ageing had a lower BMI. We also found that those with no major diseases, high physical functioning and no disability were more likely to report moderate to very good overall health status and a lower BMI. Ex-smokers were less likely to be associated with high physical functioning and active engagement with life, as compared with non-smokers.

\section{DISCUSSION}

Applying the widely used Rowe and Kahn criteria, ${ }^{(1)}$ the current study found a $25.4 \%$ prevalence of successful ageing in Singapore, an Asian country comprising multiethnic older adults. Our prevalence rate was higher than the mean value reported across European countries (8.5\%) and the highest prevalence rate of successful ageing from Denmark (21.1\%). ${ }^{(10)}$ In addition, it was higher than that reported by McLaughlin et $\mathrm{al}^{(9)}$ in the US $(11.9 \%)$ and Liu et al in China (13.2\%). However, the studies from the US and Europe were conducted among older adults aged $\geq 65$ years, as compared with $\geq 60$ years in our cohort. In an effort to make our findings comparable with those of our Western counterparts, we estimated the prevalence of active 


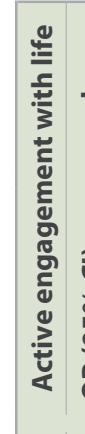

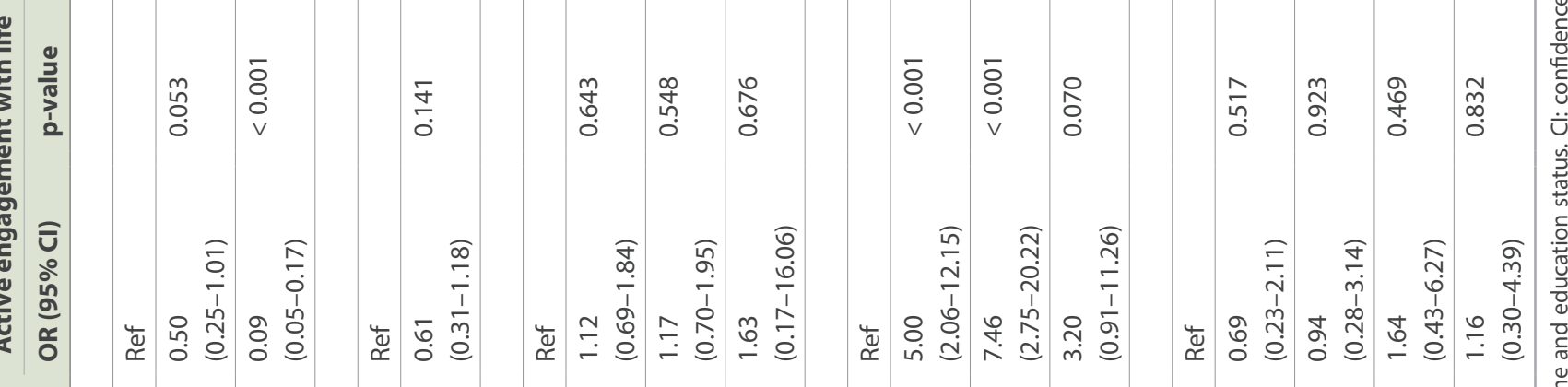

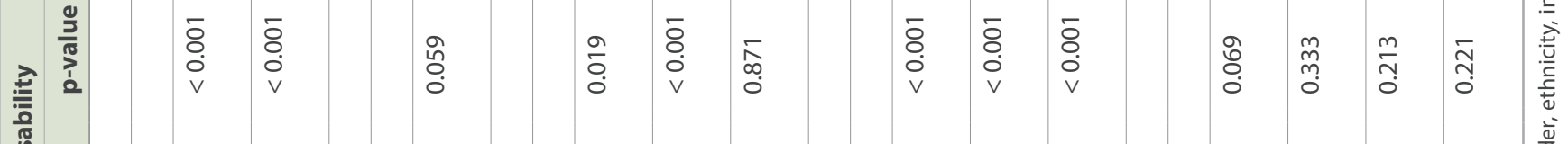

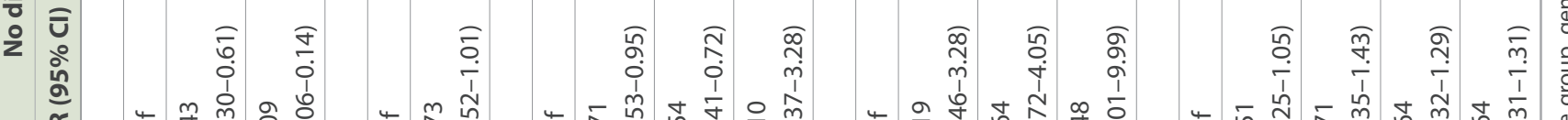

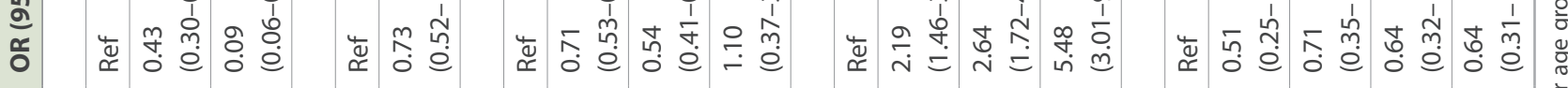

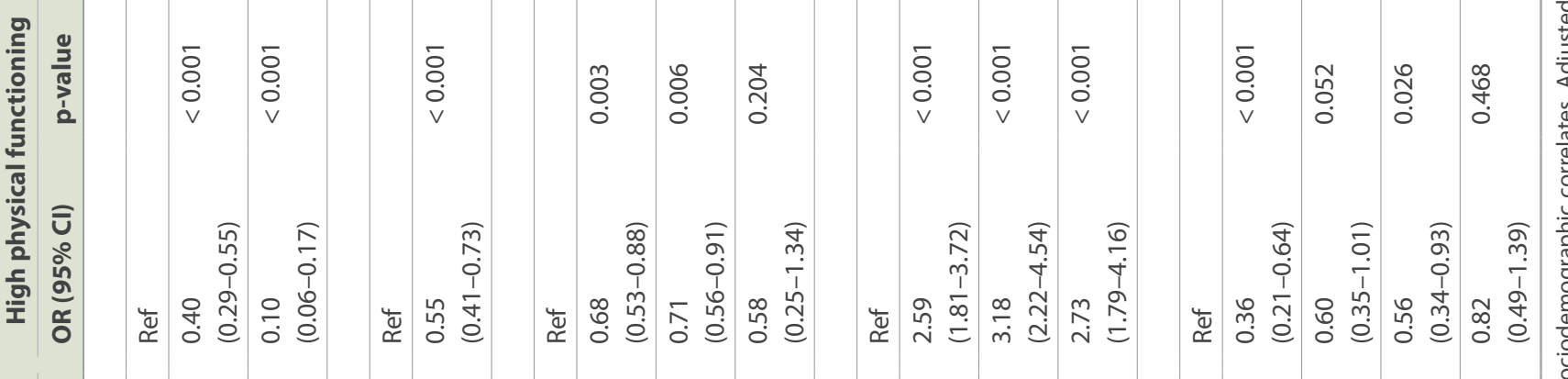

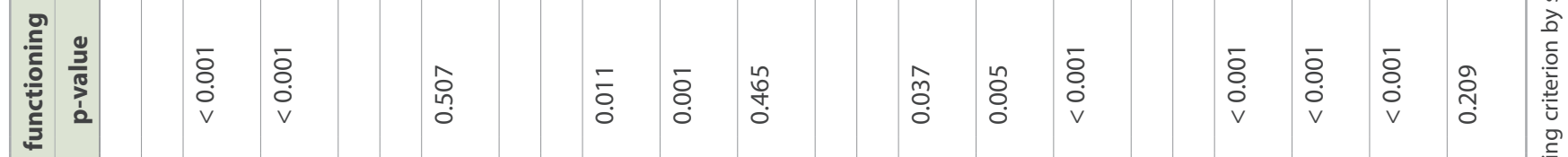

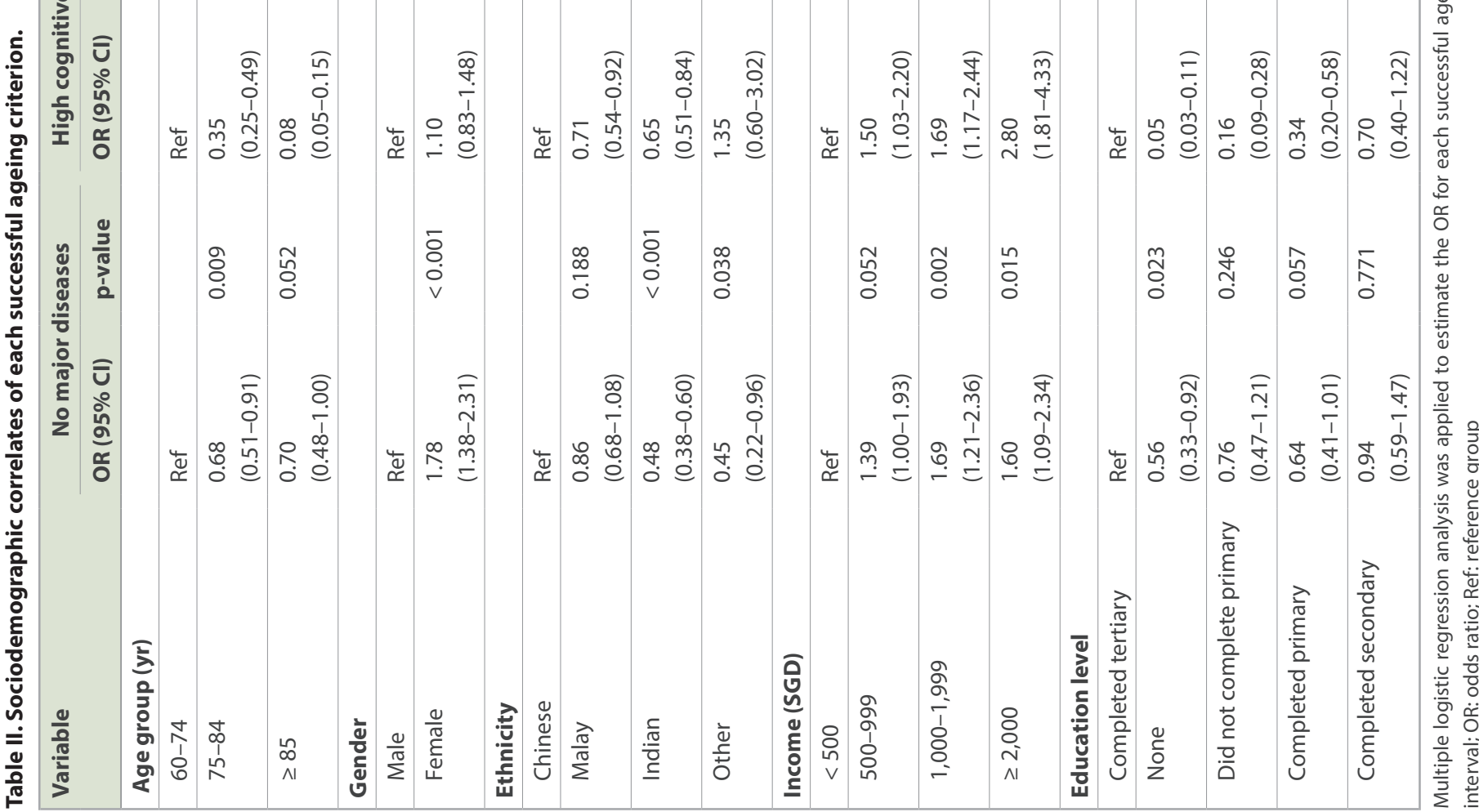


Table III. Sociodemographic correlates of successful ageing.

\begin{tabular}{|c|c|c|c|c|}
\hline \multirow[t]{2}{*}{ Variable } & \multicolumn{2}{|c|}{ Successful ageing [No. (weighted \%)] } & \multicolumn{2}{|c|}{ Multiple logistic regression } \\
\hline & No & Yes & OR (95\% CI) & p-value \\
\hline Overall sample & $2,128(74.6)$ & $437(25.4)$ & & \\
\hline \multicolumn{5}{|l|}{ Age group (yr) } \\
\hline $60-74$ & $1,108(68.4)$ & $386(31.6)$ & Ref & \\
\hline $75-84$ & $628(92.3)$ & $41(7.7)$ & $0.3(0.2-0.4)$ & $<0.001$ \\
\hline$\geq 85$ & $392(96.8)$ & $10(3.2)$ & $0.1(0.1-0.3)$ & $<0.001$ \\
\hline \multicolumn{5}{|l|}{ Gender } \\
\hline Male & $878(72.0)$ & $239(28.0)$ & Ref & \\
\hline Female & $1,250(76.7)$ & $198(23.3)$ & $1.1(0.8-1.6)$ & 0.423 \\
\hline \multicolumn{5}{|l|}{ Ethnicity } \\
\hline Chinese & $787(72.9)$ & $225(27.1)$ & Ref & \\
\hline Malay & $654(84.2)$ & $91(15.8)$ & $0.6(0.4-0.8)$ & 0.001 \\
\hline Indian & $657(82.4)$ & $115(17.6)$ & $0.5(0.4-0.7)$ & $<0.001$ \\
\hline Others & $30(82.1)$ & $6(17.9)$ & $0.4(0.2-1.0)$ & 0.049 \\
\hline \multicolumn{5}{|l|}{ Income* (SGD) } \\
\hline$<500$ & $933(87.9)$ & $74(12.1)$ & Ref & \\
\hline $500-999$ & $406(75.5)$ & $70(24.5)$ & $2.0(1.2-3.3)$ & 0.004 \\
\hline $1,000-1,999$ & $392(69.8)$ & $138(30.2)$ & $2.1(1.3-3.2)$ & 0.001 \\
\hline$\geq 2,000$ & $239(59.6)$ & $124(40.4)$ & $2.4(1.5-3.9)$ & $<0.001$ \\
\hline \multicolumn{5}{|l|}{ Education level $^{+}$} \\
\hline Completed tertiary & $172(59.8)$ & $90(40.0)$ & Ref & \\
\hline None & $494(92.6)$ & $17(7.4)$ & $0.2(0.1-0.3)$ & $<0.001$ \\
\hline Did not complete primary & $560(83.6)$ & $60(16.4)$ & $0.4(0.2-0.6)$ & $<0.001$ \\
\hline Completed primary & $532(76.7)$ & $108(23.3)$ & $0.5(0.3-0.8)$ & 0.002 \\
\hline Completed secondary & $355(57.5)$ & $162(42.5)$ & $1.02(0.6-1.6)$ & 0.932 \\
\hline
\end{tabular}

Adjusted for age group, gender, ethnicity, income and education status. *Based on National Survey of Senior Citizens 2011 report. †Data on education levels was not available for some respondents. Cl: confidence interval; OR: odds ratio; Ref: reference group

Table IV. Association between the individual criteria of successful ageing and overall health, smoking status and BMI.

\begin{tabular}{|c|c|c|c|c|c|c|c|c|}
\hline \multirow[t]{2}{*}{ Criterion } & \multicolumn{2}{|c|}{ Overall health* } & \multicolumn{2}{|c|}{ Ex-smoker $^{+}$} & \multicolumn{2}{|c|}{ Current smoker } & \multicolumn{2}{|c|}{ BMI } \\
\hline & OR (95\% CI) & p-value & OR $(95 \% \mathrm{Cl})$ & p-value & OR $(95 \% \mathrm{Cl})$ & p-value & $\beta(95 \% \mathrm{CI})$ & p-value \\
\hline No major diseases & $\begin{array}{l}2.51 \\
(1.09-5.76)\end{array}$ & 0.031 & $\begin{array}{l}0.76 \\
(0.53-1.10)\end{array}$ & 0.151 & $\begin{array}{l}0.94 \\
(0.62-1.43)\end{array}$ & 0.765 & $\begin{array}{l}-0.50 \\
(-0.98 \text { to }-0.01)\end{array}$ & 0.046 \\
\hline $\begin{array}{l}\text { High cognitive } \\
\text { functioning }\end{array}$ & $\begin{array}{l}1.98 \\
(0.65-6.06)\end{array}$ & 0.231 & $\begin{array}{l}1.52 \\
(0.99-2.32)\end{array}$ & 0.054 & $\begin{array}{l}1.19 \\
(0.75-1.91)\end{array}$ & 0.457 & $\begin{array}{l}0.09 \\
(-0.45 \text { to } 0.63)\end{array}$ & 0.746 \\
\hline $\begin{array}{l}\text { High physical } \\
\text { functioning }\end{array}$ & $\begin{array}{l}6.62 \\
(1.99-22.04)\end{array}$ & 0.002 & $\begin{array}{l}0.66 \\
(0.44-0.98)\end{array}$ & 0.041 & $\begin{array}{l}1.47 \\
(0.89-2.44)\end{array}$ & 0.135 & $\begin{array}{l}-0.69 \\
(-1.27 \text { to }-0.11)\end{array}$ & 0.020 \\
\hline No disability & $\begin{array}{l}4.52 \\
(1.85-11.06)\end{array}$ & 0.001 & $\begin{array}{l}0.69 \\
(0.44-1.07)\end{array}$ & 0.100 & $\begin{array}{l}1.90 \\
(0.99-3.62)\end{array}$ & 0.052 & $\begin{array}{l}-0.89 \\
(-1.65 \text { to }-0.13)\end{array}$ & 0.022 \\
\hline $\begin{array}{l}\text { Active engagement } \\
\text { with life }\end{array}$ & $\begin{array}{l}1.91 \\
(0.69-5.28)\end{array}$ & 0.210 & $\begin{array}{l}0.40 \\
(0.18-0.91)\end{array}$ & 0.029 & $\begin{array}{l}0.64 \\
(0.16-2.47)\end{array}$ & 0.513 & $\begin{array}{l}0.38 \\
(-1.05 \text { to } 1.81)\end{array}$ & 0.600 \\
\hline Successful ageing & $\begin{array}{l}6.83 \\
(0.97-47.92)\end{array}$ & 0.053 & $\begin{array}{l}1.34 \\
(0.84-2.16)\end{array}$ & 0.221 & $\begin{array}{l}1.33 \\
(0.79-2.23)\end{array}$ & 0.289 & $\begin{array}{l}-0.73 \\
(-1.31 \text { to }-0.14)\end{array}$ & 0.015 \\
\hline
\end{tabular}

All associations were adjusted for age, gender, ethnicity, income and education status. *Moderate to very good vs. bad to very bad. $\dagger$ Ex-smokers vs. non-smokers. ‡Current-smokers vs. non-smokers. $\beta$ : beta coefficient; BMI: body mass index; Cl: confidence interval; OR: odds ratio

ageing among those aged $\geq 65$ years in our sample, and found a rate of $19.6 \%$, which was still higher than that of the US study, but lower than that of Denmark $(21.1 \%$, the country with the highest prevalence of successful ageing) and slightly higher than that of Sweden $(17.4 \%$, the country with the second highest prevalence of successful ageing in the European study). ${ }^{(10)}$
In Hank's study, ${ }^{(10)}$ the percentage of European older adults who reported no major diseases, high cognitive functioning, high physical functioning, no disability and active engagement with life was $51.0 \%, 67.2 \%, 69.4 \%, 85.9 \%$ and $42.6 \%$, respectively. The current study used similar criteria for no major diseases, high cognitive functioning (using different instruments) and 
active engagement with life. Compared with Hank's study, the percentage of older adults in our study who reported no major diseases is almost similar, while that of the other two criteria showed significant differences. Despite their lower cognitive and physical functioning, older adults in Singapore tended to have much higher active engagement with life. This high level of active engagement in our population could be due to several factors, many of which are either policy or societal driven. While the standard retirement age in Singapore is 62 years, as part of the Retirement and Re-employment Act (revised 2012), employers are required to offer re-employment opportunities until employees reach the age of 67 years. ${ }^{(28)}$ Thus, older adults in Singapore are more likely to be employed as compared to those in other countries. ${ }^{(29)}$ Additionally, Wu and Chan had an interesting hypothesis that the public housing system in Singapore plays a positive role in social interaction in Singapore. They suggested that the built environment of the public housing blocks leads to close physical proximity with neighbours and that these well-equipped urban communities provide social support services for older adults. With easy access to amenities such as libraries, healthcare services, day activity centres and community centres, these individuals are able to form social networks that grow stronger with the length of residence in a particular area. ${ }^{(30)}$ Cross-country comparisons can, therefore, identify differences in specific domains and encourage knowledge transfer, wherein countries can learn from each other and promote best practices to enable older adults to age successfully.

In the present study, the prevalence of successful ageing varied according to demographic factors, with lower odds of successful ageing among those with advancing age, lower education and lower income. These findings have been reflected in other studies. ${ }^{(9-11)}$ The negative association between age and successful ageing is not unexpected. Biological ageing is characterised by cellular degeneration, leading to increases in chronic diseases and disability with age, ${ }^{(31,32)}$ along with a decline in cognition, functioning and interactions. ${ }^{(3,34)}$ As for education and income, they may interact with multiple domains and with each other to influence successful ageing. It is possible that older persons with higher income have greater access to health promoting resources and healthcare. ${ }^{(35,36)}$ Those with higher education may possess greater knowledge and skills that enable them to exhibit positive health behaviours related to diet, exercise, self-efficacy and personal control, ${ }^{(37)}$ leading to lower risks of chronic illness and disability. It is also possible that they have higher cognitive functioning, as suggested by the cognitive reserve theory, which may aid in successful ageing. ${ }^{(20)}$

Similar to our study, McLaughlin et al also observed ethnic differences in successful ageing. They reported that non-white people were less likely to age successfully as compared to their white counterparts, although this difference was not significant after adjusting for covariates, and concluded that socioeconomic differences in the two groups may have contributed to the differences in the prevalence of successful ageing. ${ }^{(9)}$ In contrast, the differences in successful ageing in our study persisted despite adjusting for covariates. Our data suggests that the proportion of those reporting no major disease was lower among the Indians, while the proportion of those who met the criterion for high cognitive functioning was lower among those of Indian and Malay ethnicities as compared to the Chinese. These differences were also observed in the adjusted analysis and may have contributed to the lower physical functioning and higher disability levels seen in older adults of Indian and Malay ethnicities as compared to those of Chinese ethnicity, thus resulting in lower rates of successful ageing in these two ethnicities.

No major disease, high physical functioning and no disability were significantly associated with self-reported health status of 'moderate, good or very good', although high cognitive functioning and active engagement with life criteria were not correlated with this status. Successful ageing showed a trend towards significance in terms of association with 'moderate, good or very good' status. Bowling suggested that self-reported health status is an important component of a multidimensional model of ageing, ${ }^{(6)}$ which supports the concept of successful ageing as measured in the current study. Lower BMI was associated with successful ageing as well as no major disease, high physical functioning and no disability. Studies have suggested that obesity is associated with chronic physical conditions, ${ }^{(38)}$ while loss of muscle mass and increased body fat may be associated with disability and even frailty, ${ }^{(39)}$ which may have led to both poorer health and disability among older adults in the current study. Additionally, ex-smokers were less likely to be associated with high physical functioning; it is possible that those who had some health problems had opted to quit smoking, while those with no discernible adverse effects continued to smoke, leading to the lack of association between current smokers and successful ageing for this criteria. The association of low BMI and nonsmoking status with successful ageing suggests the presence of modifiable risk factors, which can be targeted earlier in life to promote successful ageing.

The current study has certain limitations that should be considered in the interpretation of its findings. First, the response rate of the study was $65.6 \%$, and it is possible that those who chose not to participate were more physically unwell or cognitively impaired than those who participated in the study. Thus the prevalence of successful ageing may have been overestimated. Second, although we did our best to standardise the criteria for successful ageing against three recent studies, we were only partially successful. We used more objective measures as criteria for high physical functioning than the other studies, which may have resulted in differences that limit comparability. Third, the choice of physical conditions was arbitrary; using a different set or a larger number of conditions could have affected the prevalence of successful ageing in the current study. Fourth, as stated in the introduction of this paper, the study was limited by the use of Rowe and Kahn's criteria, (1) which excluded older adults' perception of successful ageing. The study also omitted interactions between sociodemographic factors, such as between gender and ageing or between gender and education, which may 
have provided other unique findings. While previous studies have identified common themes across all ethnicities in Singapore, including physical health and social relationships, the salient role of spirituality/religiosity, which was identified mainly by Indian and Malay older adults, was not explored in the study. ${ }^{(14-16)}$ Lastly, we did not study the effects of other important correlates, such as diet and resilience, and their impact on successful ageing. Future research needs to address some of these gaps, including understanding intercultural differences in the definition of and the factors affecting successful ageing.

Ageing is a complex and multifactorial process that involves both primary ageing processes (inevitable deterioration of cellular structure and function independent of disease $)^{(40)}$ and the effects of secondary ageing (resulting from chronic disease and lifestyle behaviours). ${ }^{(41,42)}$ Primary ageing associated with structural and functional deterioration will have an impact on functioning over a lifespan and can lead to disability in older adults. On the other hand, secondary ageing can be prevented or its course modified. Data from the Framingham Heart Study has shown that in middle age, having lower levels of cardiovascular risk factors, including lower blood pressure and serum cholesterol levels, absence of glucose intolerance and non-smoking status, can predict survival and, importantly, major morbidity-free survival to age 85 years. ${ }^{(43)}$ Studies have also shown that regular exercise can counteract some of the adverse physiological, psychological and cognitive consequences of chronic disease risk factors, ${ }^{(44,45)}$ as well as positively influence them. ${ }^{(46,47)}$ Exercise may also be associated with mental well-being, ${ }^{(48)}$ satisfaction with life and social integration ${ }^{(49,50)}$ - all of which are components of successful ageing.

Singapore has taken a proactive approach to encourage successful ageing. The focus is on individual responsibility for health, with the family seen as a major source of support and institutional care regarded as a last resort. However, there is an increasing realisation that seniors, families, communities and the state must all work together to ensure the well-being of older adults. ${ }^{(51)}$ Initiatives such as the 'Many Helping Hands' approach encourage the participation of community-based voluntary welfare organisations and grassroots organisations to help in delivering services. ${ }^{(52)}$ To ensure intergenerational bonding and prevent intergenerational tensions, a taskforce was set up to promote 'grandparenting' and intergenerational bonding, through encouraging intergenerational initiatives and raising awareness of the benefits of such bonding. ${ }^{(53)}$

Thus, successful ageing can be facilitated by employing intergenerational initiatives such as 'Many Helping Hands'. Individuals must take responsibility for their health by adopting healthy lifestyles such as healthy dietary habits, avoidance of smoking and regular exercise to prevent secondary ageing and ameliorate the functional decline associated with primary ageing. Families and communities can help in this process by supporting older adults in their adoption of a healthy lifestyle over their lifespan and by assisting them to age in place through providing support and ensuring their continued integration into society.

\section{ACKNOWLEDGEMENTS}

This study was funded by the Ministry of Health, Singapore, and the Singapore Millennium Foundation of the Temasek Trust.

\section{REFERENCES}

1. Rowe JW, Kahn RL. Successful aging. Gerontologist 1997; 37:433-40.

2. Peel NM, McClure RJ, Bartlett HP. Behavioral determinants of healthy aging. Am J Prev Med 2005; 28:298-304.

3. Baltes PB, Baltes MM, eds. Successful Aging. Perspectives from the Behavioral Sciences. New York: Cambridge University Press, 1990; 8.

4. Butler RN. What is 'successful' aging? Geriatrics 1988; 43:15.

5. Pruchno RA, Wilson-Genderson M, Rose M, Cartwright F. Successful aging: early influences and contemporary characteristics. Gerontologist 2010; 50:821-33.

6. Bowling A. Lay perceptions of successful ageing: findings from a national survey of middle aged and older adults in Britain. Eur J Ageing 2006; 3:123-36.

7. Phelan EA, Anderson LA, LaCroix AZ, Larson EB. Older adults' views of "successful aging" - how do they compare with researchers' definitions? J Am Geriatr Soc 2004; 52:211-6.

8. Dillaway HE, Byrnes M. Reconsidering successful aging: a call for renewed and expanded academic critiques and conceptualizations. J Appl Gerontol 2009; 28:702-22.

9. McLaughlin SJ, Connell CM, Heeringa SG, Li LW, Roberts JS. Successful aging in the United States: prevalence estimates from a national sample of older adults. J Gerontol B Psychol Sci Soc Sci 2010; 65B:216-26.

10. Hank K. How "successful" do older Europeans age? Findings from SHARE. J Gerontol B Psychol Sci Soc Sci 2011; 66:230-6.

11. Liu H, Byles JE, Xu X, et al. Evaluation of successful aging among older people in China: results from China health and retirement longitudinal study. Geriatr Gerontol Int 2017; 17:1183-90.

12. Ministry of Health, Singapore. Population and vital statistics. Available at: https:// www.moh.gov.sg/content/moh_web/home/statistics/Health_Facts_Singapore/ Population_And_Vital_Statistics.html. Accessed April 22, 2018.

13. International Longevity Centre, Singapore. A profile of older men and women in Singapore 2011. Available at: https://www.duke-nus.edu.sg/care/wp-content/ uploads/Profile_Of_Older_MenWomen.pdf. Accessed April 22, 2018.

14. Nagalingam J. Understanding successful aging: a study of older Indian adults in Singapore. Care Manag J 2007; 8:18-25.

15. Tohit N, Browning CJ, Radermacher $\mathrm{H}$. 'We want a peaceful life here and hereafter': healthy ageing perspectives of older Malays in Malaysia. Ageing Soc 2012; 32:405-24.

16. Gwee X. Ageing well: studies of its global and multidomain and construct among multi-ethnic Singaporean seniors (doctoral thesis). Singapore: National University of Singapore, 2013.

17. Ng TP, Broekman BF, Niti M, Gwee X, Kua EH. Determinants of successful aging using a multidimensional definition among Chinese elderly in Singapore. Am J Geriatr Psychiatry 2009; 17:407-16

18. Ng TP, Leong T, Chiam PC, Kua EH. Ethnic variations in dementia: the contributions of cardiovascular, psychosocial and neuropsychological factors. Dement Geriatr Cogn Disord 2010; 29:131-8.

19. Subramaniam M, Chong SA, Vaingankar JA, et al. Prevalence of dementia in people aged 60 years and above: results from the WiSE study. J Alzheimers Dis 2015; 45:1127-38.

20. Copeland JR, Kelleher MJ, Kellett JM, et al. A semi-structured clinical interview for the assessment of diagnosis and mental state in the elderly: the Geriatric Mental State schedule. I. Development and reliability. Psychol Med 1976; 6:439-49.

21. Subramaniam M, Abdin E, Sambasivam R, et al. Prevalence of depression among older adults: results from the Well-being of the Singapore Elderly study. Ann Acad Med Singapore 2016; 45:123-33.

22. Ong HL, Chang $\mathrm{SH}$, Abdin $\mathrm{E}$, et al. Association of grip strength, upper arm circumference, and waist circumference with dementia in older adults of the WiSE study: a cross-sectional analysis. J Nutr Health Aging 2016; 20:996-1001.

23. Shafie S, Shahwan S, Abdin E, et al. The correlates of slow gait and its relation with social network among older adults in Singapore. Aging Ment Health 2016; 19:1-6.

24. Depp CA, Jeste DV. Definitions and predictors of successful aging: a comprehensive review of larger quantitative studies. Am J Geriatr Psychiatry 2006; 14:6-20.

25. Hall KS, Hendrie HH, Rodgers DD, et al. The development of a dementia screening interview in two distinct languages. Int J Methods Psychiatry 1993; $3: 1-28$.

26. Ganguli M, Chandra V, Gilby JE, et al. Cognitive test performance in a community-based nondemented elderly sample in rural India: the Indo-US Cross-National Dementia Epidemiology Study. Int Psychogeriatr 1996; 8:507-24.

27. Pang S, Subramaniam M, Abdin E, et al. Prevalence and predictors of tobacco use in the elderly. Int J Geriatr Psychiatry 2016; 31:716-22.

28. Ministry of Manpower, Singapore. Employment practices: retirement. Available 
at: https://www.mom.gov.sg/employment-practices/re-employment. Accessed April 20, 2018.

29. Tan ME, Sagayadevan V, Abdin E, et al. Employment status among the Singapore elderly and its correlates. Psychogeriatrics 2017; 17:155-63.

30. Wu T, Chan A. Families, friends, and the neighborhood of older adults: evidence from public housing in Singapore. J Aging Res 2012; 2012:659806.

31. Wolff JL, Starfield B, Anderson G. Prevalence, expenditures, and complications of multiple chronic conditions in the elderly. Arch Intern Med 2002; 162:2269-76.

32. Wilkins K, Park E. Chronic conditions, physical limitations and dependency among seniors living in the community. Health Rep 1996; 8:7-15.

33. Glisky EL. Changes in Cognitive Function in Human Aging. In: Riddle DR, ed. Brain Aging: Models, Methods, and Mechanisms. Boca Raton, FL: CRC Press/ Taylor and Francis, 2007: 3-20.

34. Deary IJ, Corley J, Gow AJ, et al. Age-associated cognitive decline. Br Med Bull 2009; 92:135-52.

35. Galobardes B, Shaw M, Lawlor DA, Davey Smith G, Lynch J. Indicators of socioeconomic position. In: Oakes JM, Kaufman JS, eds. Methods in social epidemiology. San Francisco, CA: Jossey-Bass, 2006: 47-85.

36. Preston $\mathrm{SH}$, Taubman $\mathrm{P}$. Socioeconomic differences in adult mortality and health status. In: Martin LG, Preston SH, eds. Demography of Aging. Washington, DC: National Academy Press, 1994: 279-318.

37. House JS, Lepkowski JM, Kinney AM, et al. The social stratification of aging and health. J Health Soc Behav 1994; 35:213-34

38. Visscher TL, Seidell JC. The public health impact of obesity. Annu Rev Public Health $2001 ; 22: 355-75$.

39. Blaum CS, Xue QL, Michelon E, Semba RD, Fried LP. The association between obesity and the frailty syndrome in older women: the Women's Health and Aging Studies. J Am Geriatr Soc 2005; 53:927-34.

40. Holloszy JO. The biology of aging. Mayo Clin Proc 2000; 75 Suppl: S3-9.

41. Masoro EJ, ed. Handbook of Physiology Section 11 - Aging. New York, NY: Oxford University Press, 1995: 3-21.

42. Weinert BT, Timiras PS. Invited review: theories of aging. J Appl Physiol (1985)
2003; 95:1706-16

43. Terry DF, Pencina MJ, Vasan RS, et al. Cardiovascular risk factors predictive for survival and morbidity-free survival in the oldest-old Framingham Heart Study participants. J Am Geriatr Soc 2005; 53:1944-50.

44. American College of Sports Medicine, Chodzko-Zajko WJ, Proctor DN, et al. American College of Sports Medicine position stand. Exercise and physical activity for older adults. Med Sci Sports Exerc 2009; 41:1510-30.

45. Northey JM, Cherbuin N, Pumpa KL, Smee DJ, Rattray B. Exercise interventions for cognitive function in adults older than 50: a systematic review with metaanalysis. Br J Sports Med 2018; 52:154-60.

46. Weinstein AR, Sesso HD. Joint effects of physical activity and body weight on diabetes and cardiovascular disease. Exerc Sport Sci Rev 2006; 34:10-5.

47. Tuomilehto J, Lindström J, Eriksson JG, et al. Finnish Diabetes Prevention Study Group. Prevention of type 2 diabetes mellitus by changes in lifestyle among subjects with impaired glucose tolerance. N Engl J Med 2001; 344:1343-50.

48. Rosenbaum S, Sherrington $\mathrm{C}$. Is exercise effective in promoting mental wellbeing in older age? A systematic review. Br J Sports Med 2011; 45:1079-80.

49. McAuley E, Blissmer B, Marquez DX, et al. Social relations, physical activity, and well-being in older adults. Prev Med 2000; 31:608-17.

50. Elavsky S, McAuley E, Motl RW, et al. Physical activity enhances long-term quality of life in older adults: efficacy, esteem, and affective influences. Ann Behav Med 2005; 30:138-45.

51. Ministry of Health, Singapore. Creating Senior-Friendly Communities: Tips and Tools from the City For All Ages Project. Available at: https://www.moh.gov. sg/resources-statistics/educational-resources/cfaa-guidebook---creating-seniorfriendly-communities. Accessed April 22, 2018.

52. Rozario PA, Rosetti AL. "Many Helping Hands": a review and analysis of longterm care policies, programs, and practices in Singapore. J Gerontol Soc Work 2012; 55:641-58.

53. Thang LL. Promoting intergenerational understanding between the young and old: the case of Singapore. UN Report of the Expert Group Meeting in Qatar, March 2011. 